\title{
SISTEMATIZAÇÃO DE UMA EXPERIÊNCIA DE EDUCAÇÃO ALIMENTAR E NUTRICIONAL EM ESCOLA PÚBLICA DE
} SALVADOR-BA

\section{SYSTEMATIZATION OF AN EXPERIENCE OF FOOD AND NUTRITIONAL EDUCATION IN A PUBLIC SCHOOL OF SALVADOR-BA}

\author{
Virgínia Campos Machado ${ }^{1}$ \\ Amanda Santos Bispo ${ }^{2}$
}

\begin{abstract}
RESUMO
Este trabalho refere-se a uma experiência de Educação Alimentar e Nutricional realizada em uma escola pública de Salvador-BA. Fundamentado no método de sistematização de experiência proposto por Oscar Jara, o texto aborda a contextualização da intervenção, o processo de construção das ações, bem como uma reflexão sobre suas potencialidades e limites. As atividades sistematizadas ocorreram em uma escola de ensino fundamental I e envolveram a equipe diretiva, professoras, estudantes e merendeiras. Os resultados são apresentados em 04 eixos de discussão e abordam a reformulação dos objetivos do projeto a partir da inserção na realidade escolar; as concepções relacionadas à temática da promoção da alimentação saudável na escola compartilhadas pelas professoras; a valorização e o estigma da alimentação escolar; bem como o planejamento e realização das atividades educativas. Conclui-se afirmando a importância da sistematização de experiências como estratégia de fortalecimento da tríade ação-reflexão-ação no campo da educação alimentar e nutricional.
\end{abstract}

Palavras-chaves: promoção da alimentação saudável; educação alimentar e nutricional; alimentação escolar.

\section{ABSTRACT}

This paper refers to an experience of Food and Nutrition Education conducted in a public school in Salvador-BA. Based on the method of systematization of experience proposed by Oscar Jara, the text addresses the contextualization of the intervention, the process of construction of actions, as well as a reflection on its potentialities and limits. The systematized activities took place in an elementary school I and involved the management team, teachers, students and lunchmakers. The results are

\footnotetext{
${ }^{1}$ Doutora em Educação (Psicologia da Educação) pela Pontifícia Universidade Católica de São Paulo. Atualmente é Docente da área de Ciências Sociais e Humanas em Saúde do Departamento de Ciências da Nutrição da Universidade Federal da Bahia. e-mail: virginia.campos@ufba.br

${ }^{2}$ Possui graduação em Bacharelado Interdisciplinar em Saúde pela Universidade Federal da Bahia. Graduanda em Nutrição pela Universidade Federal da Bahia, membro do Grupo de Pesquisa e Extensão do Restaurante Universitário - GPERU/UFBA. e-mail: amandasantosbispo@gmail.com.
} 
presented in four axes of discussion and address the reformulation of the project objectives from the insertion in the school reality; the conceptions related to the theme of promoting healthy eating at school shared by the teachers; the appreciation and stigma of school feeding; as well as the planning and implementation of educational activities. We conclude by stating the importance of systematizing experiences as a strategy for strengthening the action-reflection-action triad in the field of food and nutrition education.

Keywords: promotion of healthy eating; food and nutrition education; school feeding.

\section{INTRODUÇÃO}

Ao longo do tempo, pode-se observar que a função da escola é compreendida de diferentes maneiras. Antes do processo de revolução industrial, o ensino tinha um caráter enciclopédico, a quantidade era mais valorizada que a qualidade. Mesmo após a revolução industrial, a função da escola continua consolidada como transmissora da experiência social historicamente acumulada, mas a mesma passa a ter um caráter tecnicista, ligado à necessidade de formação de mão-de-obra para o trabalho industrial. Os movimentos críticos a essa interpretação ganham força no Brasil nos anos 1930, com a Escola Nova (MIZUKAMI, 1986; LEÃO, 1999).

Na década de 1980, os questionamentos à escola tradicional se colocam no contexto do construtivismo, com a introdução da obra de Jean Piaget, bem como de outros autores construtivistas. Nessa perspectiva, a educação tem como foco a teoria da ação (a teoria enquanto realidade pensada), privilegiando-se o processo mais que o produto. A função da escola é compreendida como trabalhar para que cada discente se torne um cidadão capaz de entender a realidade em que vive e saiba lutar pelos seus direitos (LEÃO, 1999).

O compromisso com a formação cidadã imprime mudanças no currículo da escola. No Brasil, o fortalecimento da luta pela cidadania permitiu o avanço do trabalho educativo em saúde, desde novas concepções teóricas a práticas educativas em saúde no cotidiano didáticopedagógico das escolas, tornando-a importante parceira nas ações de melhoria e formação de hábitos alimentares (BRASIL, 2007; ALBUQUERQUE, 2012; CAMOZZI, 2015). 
A inclusão das diretrizes da Promoção da Alimentação Saudável nas Escolas (PAS) (BRASIL, 2006) como parte do projeto político pedagógico visa estimular a construção de uma gestão democrática a partir da relação escola e comunidade (CERVATO-MANCUSO ET AL, 2013). A implantação de outros programas e políticas públicas que abordam a Educação Alimentar e Nutricional (EAN) também contribui para a inclusão deste tema no cotidiano escolar (BRASIL, 2007; BRASIL, 2009; BRASIL, 2012).

Apesar disso, estudos sobre as ações de EAN no contexto escolar demonstram um distanciamento entre os discursos e as práticas, com a coexistência de pedagogias críticas e o enfoque em modelos tradicionais e comportamentais (SANTOS, 2012; RAMOS ET AL, 2013). A ênfase à abordagem tecnicista também foi observada, com prevalência de atividades que tentam relacionar o alimento à sua composição nutricional, tendo o profissional nutricionista como detentor desse saber. A utilização de estratégias participativas e problematizadoras ainda é tímida (BORSOI; TEO; MUSSIO; 2016).

A superação da lógica reducionista centrada na transmissão da informação, bem como a realização da EAN como “[...] campo de conhecimento e de prática contínua e permanente, transdisciplinar e multiprofissional que visa promover a prática autônoma e voluntária de hábitos alimentares saudáveis" (BRASIL, 2012, p.23), exigem uma postura crítica e reflexiva daqueles que trabalham com EAN (CERVATO-MANCUSO; VINCHA; SANTIAGO, 2016).

A prática-reflexiva fortalece processos de ação-reflexão-ação e deve ser adotada como exercício permanente, possibilitando melhorar a qualidade das atividades desenvolvidas por meio da ação pedagógica (SCHMITT, 2011). Para Paulo Freire (1996, p.18), a reflexão sobre a prática atual deve ser crítica a fim de melhorar a próxima prática. Através dessa reflexão, é preciso possibilitar que a curiosidade ingênua se torne crítica.

No entanto, não basta apenas interpretar as experiências, é preciso que estas se tornem comunicáveis; a ponto de que seus resultados possam gerar aprendizados possíveis de compartilhamento. Segundo Jara (2006), “aprender e compartilhar são, assim, dois verbos que não podem ser desligados do exercício de sistematizar" (p.32), entendido como a ação de ordenar o processo vivido e seus resultados, a partir da inserção numa realidade social que nos 


\section{Revista \\ Debates Insubmissos}

permite relacionar teoria e prática, melhorando seus aspectos por meio da própria prática (JARA, 2006).

A partir dos pressupostos apresentados, este trabalho tem como objetivo sistematizar uma experiência de educação alimentar e nutricional em uma escola pública de Salvador-BA, abordando o processo de construção das ações, bem como suas potencialidades e limites.

\section{METODOLOGIA}

Este trabalho caracteriza-se por ser um estudo qualitativo, com base no método de sistematização proposto por Oscar Jara (2006). A experiência relatada foi vivenciada no contexto do projeto de pesquisa e extensão intitulado "Saúde e nutrição na escola: análises a partir dos livros didáticos e das falas de professores dos anos iniciais do ensino fundamental”. Tal projeto foi aprovado no Edital da Pró-reitoria de Assistência Estudantil 02/2017 Programa Permanecer, Universidade Federal da Bahia. A equipe de trabalho foi composta por duas estudantes do curso de Nutrição, uma gastrônoma e a professora responsável pelo projeto. Esta sistematização focalizará a experiência junto à comunidade escolar, não contemplando a análise dos livros didáticos.

As atividades sistematizadas ocorreram em uma escola pública do ensino fundamental I de Salvador - BA, em um bairro de classe popular, entre novembro de 2017 e junho de 2018. Participaram das mesmas, de forma voluntária, a diretora, a coordenadora pedagógica, 12 professoras $^{3}$, estudantes de turmas do $1^{\circ}$ ao $5^{\circ}$ ano, bem como as duas merendeiras da escola.

As informações apresentadas foram produzidas a partir de reuniões com diretora, coordenadora pedagógica e professoras; visitas às aulas; diálogo com as merendeiras; entrevistas com professoras, e das intervenções que foram construídas e realizadas a partir das etapas anteriormente citadas.

\footnotetext{
${ }^{3}$ Neste trabalho em alguns momentos adota-se a terminologia "professoras" para referir-se à maioria das entrevistadas, pois representaram $91,7 \%$ do total de pessoas entrevistas.
} 


\subsection{O método de sistematização da experiência}

Para a realização da sistematização do processo vivido em campo, utilizou-se o método de Sistematização, segundo Oscar Jara (2006). Para o autor, apenas quando se compreende de forma profunda a experiência realizada, é que se torna possível compartilhar aprendizagens, identificar e construir abordagens teóricas que contribuem no aprimoramento das práticas. Seu método é dividido em cinco etapas, como descritas abaixo:

A primeira etapa, "O ponto de partida", ocorre ao longo da experiência e consiste no registro do processo vivido em campo. Para isso é preciso ter participado da experiência. Neste trabalho, os registros foram feitos por meio de anotações dos diálogos com os atores participantes desse processo, das entrevistas, da análise das entrevistas, e também de registros fotográficos das intervenções e da produção de material de apoio para ações de EAN.

Passando à segunda etapa, "As perguntas iniciais", Oscar Jara (2006) indica que se deve indagar sobre o que se quer sistematizar, delimitar o objeto a ser sistematizado e definir os eixos que se pretende sistematizar. Para o propósito deste estudo, a sistematização incidirá sobre a construção de ações de educação alimentar e nutricional na escola e seus desafios. Para tanto, foram definidos 04 (quatro) eixos: “A imersão na realidade escolar, as dificuldades e a reformulação dos objetivos do projeto", "Alimentação, nutrição e saúde na perspectiva das professoras: o reconhecimento da importância e os limites à atuação crítica e permanente", "Um olhar para a alimentação escolar: entre a valorização e o estigma" e "Planejamento e realização de intervenções: breve apresentação das práticas tornadas possíveis”.

A terceira etapa a "Recuperação do processo vivido", refere-se à reconstrução da experiência vivida, de forma organizada. Nesta etapa percorre-se novamente todo o caminho traçado até a chegada dos resultados enquanto experiência, em um processo que deve tornar evidente aspectos que possam ter sido pouco considerados no momento da experiência em si. A quarta etapa, por sua vez, destina-se ao questionamento sobre o que aconteceu e por que aconteceu, e é denominada "reflexão de fundo". Essas duas etapas são apresentadas conjuntamente neste trabalho, constituindo a próxima seção. Nessa etapa são colocadas as reflexões da equipe incluídas no projeto e contribuições da literatura. Seria desejável que os 
participantes das atividades também pudessem participar deste processo. No entanto, as atividades finais do ano letivo escolar e o fim da vigência do projeto de extensão promoveram um distanciamento da equipe, impossibilitando a construção da sistematização junto aos participantes.

A última etapa, "Os pontos de chegada", conclui a sistematização. É preciso trazer o que foi aprendido e identificar quais são as contribuições da sistematização. Apresenta-se ainda as considerações sobre as possibilidades e limites da experiência. Para Oscar Jara (2006) “a dimensão comunicativa da sistematização é um aspecto substancial e não secundário e nem optativo" (p.92). Portanto, é interessante construir materiais para que possa compartilhar com outras pessoas o que foi aprendido, objetivo que se pretende alcançar com este trabalho.

Em relação aos aspectos éticos, considerou-se os critérios da Resolução n ${ }^{\circ} 510$, de 7 de abril de 2016, que trata de pesquisas realizadas no âmbito das Ciências Humanas e Sociais. Em todas as etapas de construção desse trabalho, obteve-se consentimento dos participantes.

\section{RECUPERAÇÃO DO PROCESSO VIVIDO E REFLEXÃO DE FUNDO}

Nesta seção, passamos à discussão dos eixos da sistematização. Na construção dos mesmos recupera-se a vivência e, então, busca-se refletir sobre elas com criticidade. Os eixos foram definidos com o propósito de discutir temas que se mostraram relevantes e que podem gerar resultados para melhorias das estratégias de educação alimentar e nutricionais no âmbito escolar.

\subsection{A imersão na realidade escolar, as dificuldades e a reformulação dos objetivos}

O primeiro contato com a escola se deu em novembro de 2017 e teve como objetivo apresentar o projeto à equipe gestora da escola e verificar se conseguiríamos o consentimento para desenvolvimento das atividades. Inicialmente, conversamos com a diretora da escola e apresentamos os objetivos e metodologia de trabalho. Neste ponto, destacamos que o projeto tinha como objetivo inicial conhecer os sentidos de saúde, alimentação e nutrição a partir da análise dos livros didáticos e da entrevista com professores e que propúnhamos, como parte 
das atividades, a realização de uma formação com os docentes com a intenção de que os mesmos incluíssem ações de educação alimentar e nutricional em sua atividade docente.

A diretora avaliou positivamente a proposta, mas ponderou que as professoras deveriam ser consultadas, e se disponibilizou a ceder um espaço de um momento de reunião para que tivéssemos o contato direto com elas. Após a apresentação do projeto às professoras, seguiram-se comentários que avaliavam positivamente nossa intenção, mas destacavam recorrentemente que o trabalho com a família dos estudantes deveria ser o foco de nossa ação, pois o núcleo familiar era o maior influenciador e responsável pelo comportamento alimentar dos mesmos. Essa percepção também foi encontrada no estudo realizado por Picoli e Côrrea (2013), em que a maioria dos docentes entrevistados consideraram a família como maior responsável pela alimentação dos estudantes, tanto por ser responsável pela compra e preparo dos alimentos, quanto por ser o primeiro grupo social de convívio, atuando na transmissão de hábitos alimentares e culturais.

Concordamos com as ponderações feitas pelas docentes, uma vez que também sustentamos que deve existir articulação entre a família e a escola no processo de formação das crianças. No entanto, percebemos que o trabalho com as professoras seria desafiador visto que, na medida em que apontavam a necessidade de atuação junto às famílias, não aprofundavam o papel da escola na promoção da alimentação saudável, nem na mobilização da comunidade.

Insistindo na intenção de desenvolver ações junto às docentes, passamos a questionar se as mesmas realizavam atividades que tivessem como foco a alimentação. Nesse primeiro momento de reunião com as professoras foi possível conhecer o ambiente escolar, a relação com a PAS, quais estratégias já tinham sido desenvolvidas por elas e quais foram seus resultados. Uma das professoras destacou trabalhos que foram realizados na escola, como o uso da pirâmide alimentar para demonstrar aos estudantes os grupos alimentares, e o uso de revistas e textos para dizer "o que pode e o que não pode comer". Picoli e Côrrea (2013), também destaca pirâmide alimentar e cartazes como mais frequentemente utilizados por educadores nas intervenções de EAN. 
Nesta mesma reunião, foram relatados os alimentos consumidos pelos estudantes no ambiente escolar, dando ênfase aos processados e ultraprocessados trazidos de casa como opção de lanches. Então, as professoras e a diretora solicitaram que os trabalhos fossem desenvolvidos com foco na apresentação da importância do consumo de frutas e verduras, em como os industrializados afetam negativamente a saúde e também abordássemos o cardápio da alimentação escolar.

Ao demandar esses assuntos, as professoras demonstravam sua compreensão sobre alimentação saudável e sobre o que deveria ser tematizado enquanto ação de educação alimentar e nutricional, reforçando as perspectivas tradicionais e comportamentalistas mencionadas anteriormente (RAMOS ET AL, 2013).

A partir daí, ficou acordado que faríamos visitas às salas de aulas e que, oportunamente, cada docente seria contatada para uma entrevista. Todas as salas foram visitadas, sendo possível o acompanhamento de aulas nas turmas do $4^{\circ}$ ano, especificamente das disciplinas de Português e Educação Física, de acordo com a disponibilidade da professora responsável pela turma. Tais visitas permitiram conhecer um pouco da relação entre estudantes e professoras, da rotina escolar e, ainda, identificar o interesse ou resistência das docentes em participar do projeto, mesmo que nenhuma recusa tenha sido verbalizada.

Mantivemos uma rotina de idas à escola para a realização de observações e diálogo com as professoras, mas a comunicação com esses profissionais se mostrou dificultosa. As professoras pareciam não considerar as práticas educativas em alimentação e nutrição como essenciais à sua atividade docente, mas como um "algo a mais" que pode ser agregado ao plano pedagógico. Sendo assim, acreditamos que a resistência das professoras em relação a um projeto de formação docente em práticas de EAN, decorria tanto das limitações objetivas relacionadas à falta de tempo e ao excesso de trabalho acumulado pelas docentes, quanto pelo fato de as mesmas não significarem tais práticas no bojo de sua atividade docente.

Nesse sentido, devemos destacar que todas as professoras afirmavam que a promoção da alimentação saudável na escola era relevante e que realizavam, em alguma medida, atividades sobre a temática. No entanto, os motivos para essa resposta parece ter ficado no 


\section{Revista (O) \\ Debates Insubmissos}

plano da compreensão, sem chegarem a se constituir motivos eficazes para uma ação contínua e permanente.

A diferenciação entre motivos geradores de sentidos ou motivos eficazes, e motivosestímulos ou motivos compreensíveis permite a compreensão dos sentidos atribuídos a uma situação. Enquanto os motivos eficazes têm relação pessoal com a atividade, a partir da consciência dos objetivos e fins da atividade; os motivos compreensíveis não geram sentido e possuem função impulsionadora às atividades externas ao sujeito (ASBAHR, 2014; CALVE; ROSSLER; SILVA; 2015).

As dificuldades persistiram durante o ano de 2017, período em que nossa presença serviu basicamente para a ambientação na escola. Em 2018, com a mudança da coordenadora pedagógica, precisamos reapresentar o projeto e refazer acordos, o que beneficiou o desenvolvimento das atividades deste trabalho. A coordenadora incluiu o projeto nas atividades de planejamento pedagógico na escola, contribuindo para a melhoria da relação entre nossa equipe e as professoras. Foram estabelecidos dias e horários para a realização das entrevistas e foi feita uma programação para o desenvolvimento do projeto na escola.

Notamos uma mudança no sentido atribuído ao projeto quando a coordenadora o incluiu no planejamento e o mesmo passou a compor os afazeres das professoras. No entanto, por não ser possível marcar encontros com as professoras em conjunto, o objetivo inicial do trabalho que focalizava a formação docente precisou ser reelaborado.

O desenvolvimento do projeto de extensão foi se moldando às necessidades do contexto e passamos a pensar intervenções mais pontuais que incluíssem as professoras, os estudantes e as merendeiras. Percebemos todos esses sujeitos como atores sociais, ou seja, sujeitos que desempenham papel ativo diante de uma realidade, são capazes de criar um mundo social e cultural. As análises do papel ativo dos atores sociais na escola têm foco na estruturação dos espaços, tempos e atividades escolares (DA SILVA; PÁDUA, 2010).

Para subsidiar a elaboração das intervenções, mantivemos a idéia inicial de entrevistas com as professoras e passamos a dialogar também com as merendeiras. Em relação aos alunos, não houve abordagem direta e o contato se deu nas observações de aulas. 
Apresentamos a seguir os resultados das entrevistas com as professoras, que constitui o segundo eixo da sistematização.

\subsection{Alimentação, nutrição e saúde na perspectiva das professoras: o reconhecimento da} importância e os limites à atuação crítica e permanente

As entrevistas foram realizadas com o objetivo de entender a concepção das professoras sobre os temas saúde, alimentação e nutrição e como isso contribuiria para o trabalho na escola. As entrevistas aconteceram de forma individual por meio de formulário semiestruturado, elaborado pelos pesquisadores, dividido em 04 blocos contemplando identificação dos entrevistados; concepções sobre os temas saúde, alimentação e nutrição; atuação em sala de aula e abordagens dos livros didáticos. Com total de 29 perguntas e possibilitando ao entrevistado expor sua opinião sobre os temas de forma livre.

Participaram das entrevistas 12 das 17 professoras que lecionavam nas turmas de $1^{\circ}$ ao $5^{\circ}$ ano do Ensino Fundamental I (crianças de 6 a 12 anos). Após várias tentativas fracassadas de marcar com as demais professoras, decidiu-se por não as incluir nesta etapa.

As participantes não autorizaram a gravação de áudio. Sendo assim, as respostas foram transcritas em papel no ato das entrevistas, posteriormente tabuladas no programa Excel versão 2010. A análise foi feita a partir da criação de categorias de acordo com os temas abordados na entrevista (saúde, alimentação e nutrição).

Quanto à formação profissional, 10 professoras tinham formação em Pedagogia, um em Educação Física e a um em Teatro. Rocha e Facina (2017) também encontraram em seu estudo sobre a formação de hábitos alimentares na escola a maioria dos profissionais com formação em pedagogia.

A predominância do gênero feminino entre as pedagogas é histórica e está relacionada à compreensão da mulher como cuidadora das crianças e do lar, enquanto o trabalho atribuído aos homens estava relacionado a melhores salários em setores da indústria brasileira (SILVA, 2011; GUTIERRES ET AL, 2012; CAVALCANTE; CÔRREA, 2012). A denominação “tia”, dada pelos estudantes às professoras, reforça a aproximação e identificação dessas profissionais a uma figura familiar e materna (FREIRE, 1997). 


\section{Revista \\ Debates Insubmissos}

Questionadas sobre terem formação específica para abordar os temas saúde, alimentação e nutrição, cinco entre as 12 professoras entrevistadas afirmaram não ter recebido nenhum tipo de formação específica que abordasse esses temas e apenas uma relatou formação específica durante especialização, abrangendo saúde, alimentação e nutrição. Três professoras participaram de palestras em outro espaço que não o ambiente escolar, abordando temas relacionados à higiene dos alimentos no comércio varejista, por exemplo. Três das entrevistadas mencionaram formação a partir de palestra no ambiente da escola em estudo.

$\mathrm{Na}$ faculdade não, mas tive formação na área de perecíveis e higienização quando trabalhei por muito tempo em varejo (Professora).

Sim, na especialização trabalhei com artigos. Tive disciplina de nutrição na especialização. Eu faço avaliação física funcional, anamnese, antropometria, orientação nutricional. Tiro um dia e faço essas avaliações nos "meninos" (Professora).

Podemos afirmar que a realidade encontrada na escola em que desenvolvemos o projeto faz parte de um contexto mais amplo em que os temas saúde, alimentação e nutrição não são abordados durante o processo formativo dos pedagogos ou são abordados de forma pontual. Para Pimenta e colaboradores (2017), em um estudo realizado em São Paulo com professores da Educação Infantil, há insuficiência ou mesmo inadequação dos cursos de pedagogia quanto à formação de profissionais polivalentes, visto que essa formação depende do domínio em diversas áreas de conhecimento. Entre os 144 cursos de pedagogia avaliados, do total de disciplinas ofertadas apenas $12,68 \%$ é referente a "Outros conhecimentos", como por exemplo disciplinas sobre sustentabilidade e educação ambiental; noções de epidemiologia e saúde pública; jogos online; psicopedagogia, entre outros.

Ao investigarmos as concepções de saúde, alimentação e nutrição, houve respostas como:

Saúde é estar bem com o corpo e a mente. Alimentação é ter direito garantido de fazer as refeições para ter saúde adequada. E nutrição é buscar alimentos que te proporcione uma vida de qualidade. Precisa conhecer o valor nutricional de cada alimento. Montar cardápio de acordo, também, com os recursos financeiros (Professora).

Saúde é um bem-estar geral, psicológico, físico, emocional. Nutrição é a maneira de se nutrir o corpo; qual alimento utilizar para que o corpo fique bem. E alimentação abrange... poder se alimentar bem ou mal. Mais ligado ao comportamento, influencia a família, cultural, social (Professora). 


\section{Revista \\ Debates Insubmissos}

De modo geral, as professoras entrevistadas compreendem a saúde, a alimentação e a nutrição como temas que caminham juntos. Destacam conceitos bem próximos do conceito de saúde proposto pela Organização Mundial da Saúde (OMS) em 1948, em que saúde é "um estado de completo bem-estar físico, mental e social e não somente ausência de afecções e enfermidades".

No entanto, esse conceito recebe críticas por ser firmar em uma busca incessante por um estado impecável e utópico. Utópico por ser inalcançável e estar completamente saudável em todos os aspectos que a OMS aborda, uma vez que a vida é mutável e não estável. A compressão de saúde tem relação com a subjetividade e a determinação histórica, uma vez que ter mais ou menos saúde depende do momento, do referencial e dos valores atribuídos por cada indivíduo ou sociedade (SÁ JUNIOR, 2004). Desse modo, parece pouco provável que tal conceito seja eficiente para informar as práticas de promoção da saúde e alimentação saudável das docentes, correndo-se o risco de adotarem a noção simplificada de saúde como ausência de doença.

As entrevistas também permitiram compreender que as professoras se reconhecem como influenciadoras da formação dos hábitos alimentares no ambiente escolar e buscam abordar esse tema em suas aulas. No entanto, enfatizam o papel do professor de Ciências como quem deve trabalhar em sala de aula saúde, alimentação e nutrição, como descrito nas falas abaixo:

Como tem a P2 (professora de Ciências), eu abordo de forma geral mesmo, em atividades, exemplos. Porque tem a professora de ciências que aborda isso (Professora).

Textos, desenhos, discussões, explicação sobre o consumo de sal. Eu não abordo tanto porque é da P02 (professora de Ciências). (Professora)

As professoras destacam a necessidade de que esses temas sejam "abordados de forma mais intensa. [...] precisa de um projeto mais intenso sobre isso". Rocha e Facina (2017) também ressaltam o reconhecimento dessas profissionais enquanto agentes fundamentais na promoção da alimentação saudável, porém, identificaram dificuldade em trabalhar alimentação saudável e atividade física por falta de conhecimento específico na área. 


\section{Revista \\ Debates Insubmissos}

De acordo com os relatos das professoras, a abordagem da alimentação, nutrição e saúde na sala de aula acontece por meio conversas, atividades xerocadas, apresentação das frutas e verduras, apresentações sobre alimentos saudáveis e diminuição no consumo de industrializados. Uma professora relata: "No conteúdo de ciências. Trago jogos com explicação sobre sucos de caixinhas, condimentos, sal. Mostro que fazem mal à saúde".

Em outro momento das entrevistas, quando questionadas sobre a efetividade das abordagens feitas por elas em sala de aula, as professoras avaliaram que as mesmas são pouco efetivas, possivelmente em decorrência da utilização de abordagens tradicionais. As práticas de EAN devem favorecer a problematização e o papel ativo dos educandos, favorecendo o diálogo entre indivíduos e grupos populacionais, levando em consideração as fases da vida, as etapas do sistema alimentar e as interações e significados do comportamento alimentar (BRASIL, 2012).

Os exemplos que vimos recuperando ao longo da discussão deste eixo corroboram com o imaginário social do campo da Nutrição, no qual a alimentação saudável tende a ser relacionada a teorias e práticas de prevenção e combate às doenças, assim reproduzindo ações tecnicistas e mecanicistas como nos demais saberes biomédicos contemporâneos (KRAEMER ET AL, 2014).

As professoras apresentaram em suas falas aspectos muito semelhantes aos apontados em estudos sobre a prática de EAN junto a escolares, destacando que as mesmas são voltadas para a relação entre o alimento e sua composição nutricional, pirâmide alimentar, valor nutritivo dos alimentos, alimentação saudável e fontes alimentares, e prevenção da obesidade. Quanto às metodologias, predominam as aulas expositivas e palestras (BORSOI; TEO; MUSSIO; 2016).

Estudos de intervenção desenvolvidos junto a educadores ainda se voltam a modelos tradicionais de transmissão de informações sobre hábitos alimentares saudáveis. Há estudos que evidenciam que professores relacionam o tema "alimentação saudável" ao professor de Ciências, fato que parece estar relacionado à ênfase nos aspectos biológicos, desvinculando-os da dimensão social e do prazer da alimentação. Assim, as poucas atividades voltadas para 
PAS são direcionadas, também, à disciplina de Ciências (BORSOI; TEO; MUSSIO; 2016, CAMOZZI ET AL, 2015).

A recente Lei 13.666/2018 aprovada no Diário Oficial da União que altera a Lei de Diretrizes e Bases da Educação Nacional (Lei 9.394/1996) reproduz esse viés ao incluir a Educação Alimentar e Nutricional (EAN) como tema transversal a ser abordado nas disciplinas de Ciências e Biologia nas escolas (BRASIL, 2018). Ainda que tenha o intuito de assegurar informações sobre alimentação saudável, a fim de reduzir a obesidade infantil, essa abordagem não considera que a EAN é compreendida como "[...] campo de conhecimento transdisciplinar, intersetorial e multiprofissional" (BRASIL, 2012). Desta forma, estende-se a diversos atores da comunidade escolar, e não somente a um único profissional ou disciplina.

A importância da alimentação escolar foi enfatizada pelas professoras em diversos momentos, sendo compreendida como uma alternativa saudável aos lanches industrializados que os alunos muitas vezes trazem de casa. A alimentação escolar e os diálogos com as merendeiras são analisados no próximo eixo.

\subsection{Um olhar para a alimentação escolar: entre a valorização e o estigma}

Grande parte dos diálogos que precederam o contato com as merendeiras indicavam à nossa equipe a importância de incluir no projeto a abordagem sobre a alimentação oferecida na escola. As professoras demonstravam preocupação em relação aos lanches dos escolares, quase sempre compostos por alimentos processados e/ou ultraprocessados, e afirmavam a importância e qualidade da alimentação escolar. No entanto, relataram a percepção de que a alimentação escolar tinha baixa aceitação junto aos mesmos e solicitaram sugestões ou modificações no cardápio.

De imediato, houve relutância da equipe, pois o trabalho com a alimentação escolar não fazia parte do planejamento e também porque sabíamos não poder interferir no cardápio planejado para a escola. Por outro lado, pretendíamos atender às solicitações das professoras e incluir as merendeiras como participantes do projeto.

Nesse contexto, começamos a conversar com as merendeiras, buscando encontrar um caminho para a ação que não nos levasse a repetir treinamentos de boas práticas de 
manipulação de alimentos, como muitas vezes acontece no trabalho junto à merendeiras (COSTA; LIMA; RIBEIRO, 2002; CARVALHO ET AL, 2008; GOMES, 2014).

A escola contava com duas merendeiras, que atuavam nos turnos matutino e vespertino, e deixavam preparada a alimentação para o turno noturno. O diálogo com as merendeiras aconteceu no horário de descanso e se deu como uma conversa informal sobre seu trabalho, a alimentação servida, os desafios enfrentados no cotidiano e a relação com os estudantes.

Os relatos demonstraram que o trabalho das merendeiras vai além da preparação do que está prescrito no cardápio. Apesar de seguirem o cardápio elaborado pela nutricionista responsável pela alimentação escolar, elas realizavam modificações de acordo com os alimentos disponibilizados a cada semana e também com a finalidade de tornar a alimentação mais bem aceita. Afirmavam, por exemplo, usar a beterraba para dar cor à sopa e adquirir temperos por conta própria quando os mesmos faltavam.

Esse tipo de atuação das merendeiras se relaciona à importância da alimentação escolar na vida dos escolares, visto que a alimentação na escola é um direito, e muitas vezes se torna a principal refeição no dia para um estudante. Ao modificarem as preparações alimentares ao gosto dos escolares, as merendeiras permitem não somente aceitação e equilíbrio nutricional, mas conferem dignidade ao consumo de um alimento que contemple a dimensão do prazer.

Em estudo realizado por Fernandes, Fonseca e Silva (2014), a colaboração das merendeiras em ações com estímulo à alimentação, sejam elas cotidianas ou planejadas aparecem como relevantes. Assim, reconhece-se a atuação dessas profissionais no estímulo ao aumento do consumo de legumes e verduras e a uma alimentação variada, bem como no oferecimento de todos os alimentos disponíveis na alimentação escolar e no incentivo ao consumo. As atividades de cunho educacional com foco em ações de EAN, apesar de importantes, são citadas como menos frequentes.

O estudo ainda destaca o autoreconhecimento da importância da atuação das merendeiras, que não se consideram simples cozinheiras, mas profissionais importantes ao 


\section{Revista $\bigcirc$ \\ Debates Insubmissos}

funcionamento da escola, uma vez que se elas não comparecem ao serviço os escolares são dispensados, enquanto se os professores não comparecem ao serviço, os escolares são redirecionados a outras atividades (FERNANDES; FONSECA; SILVA, 2014).

No presente trabalho, as merendeiras também se revelaram observadoras dos hábitos alimentares dos estudantes. Elas diziam saber exatamente "quem come tudo e quem deixa no prato" e reafirmavam o relatado pelas professoras quanto aos lanches como salgadinhos, refrigerantes e doces trazidos de casa, enfatizando que os alunos que levam lanche nem sempre consomem a refeição preparada por elas.

A baixa aceitação da alimentação escolar presumida pelas professoras, bem como a divisão feita pelas merendeiras entre os alunos que levam lanche e aqueles que comem a comida da escola, nos remetem ao estigma ainda relacionado à alimentação escolar. Nesse sentido, ainda que o Programa Nacional de Alimentação Escolar (PNAE) hoje seja visto como um mecanismo de garantia do Direito Humano à Alimentação Adequada (DHAA) e de permanência dos estudantes na escola, com efeitos positivos sobre a aprendizagem, persistem discursos sobre seu caráter assistencialista, que associam escolares que consomem a alimentação escolar a pobres e necessitados (SILVA ET AL, 2018).

Em estudo de Ruschel e colaboradores (2016), identificou-se que escolares pertencentes à família de estratos econômicos mais baixos (D e E) estão três vezes mais propícios ao consumo alimentar inadequado. Os autores atribuem o maior consumo de alimentos processados e/ou ultraprocessados aos custos mais baixos, mas acrescentamos que a escolha pela comida também se relaciona à dimensão simbólica. Sendo assim, apesar de a importância de consumir a alimentação escolar ser enfatizada pelas professoras, na medida em que observam a situação de vulnerabilidade dos alunos, levar o próprio lanche pode conferir ao estudante a sensação de distinção entre os demais, sendo a opção feita por estes quando possível.

O aumento do consumo de processados e/ou ultraprocessados retrata modificações feitas no padrão alimentar da população brasileira ao decorrer dos anos. Em escolares, esse 


\section{Revista (O) \\ Debates Insubmissos}

consumo pode estar associado aos hábitos alimentares, à influência da publicidade nas escolhas alimentares e a alimentação ofertada na escola (SANTOS, 2017).

Durante as conversas com as merendeiras, a composição e execução do cardápio também foi discutida. Elas se disponibilizaram a relatar, diariamente, o que havia sido preparado. Com isso, pudemos comparar o cardápio elaborado e o cardápio executado. As anotações foram feitas durante duas semanas e, em decorrência especialmente da falta de insumos, observamos que foi frequente a modificação das preparações servidas, resultando em certa monotonia alimentar. Entre as preparações que mais apareciam no cardápio estava o arroz doce e a sopa.

As merendeiras sentem-se valorizadas pelos escolares, no entanto isso não acontece por meio dos demais profissionais do ambiente escolar. Mas, assumem um papel relevante no desenvolvimento das ações do PNAE, e possuem grande relação com os estudantes. Com isso, há a necessidade de abrir espaços para essas profissionais atuarem na participação da educação, visto que seu papel na escola é mais do que a produção de refeições, incluem a aproximação com os estudantes (SZINWELSKI, 2015).

Diante disso, é importante destacar que a alimentação e nutrição nas escolas é responsabilidade dos Ministérios da Saúde e Educação, que são corresponsáveis pela garantia da alimentação e nutrição a partir da Política Nacional de Alimentação e Nutrição - PNAN (Portaria $n^{\circ}$ 2.715/2011); da Política Nacional de Alimentação Escolar - PNAE (Lei $n^{\circ}$ 11.947/2009) que, dentre seus objetivos, visa atender às necessidades, contribuindo para o desenvolvimento e crescimento biopsicossocial, e formação de hábitos alimentares por meio da educação alimentar e nutricional.

Além disso, as diretrizes da Promoção da Alimentação Saudável nas Escolas (Portaria Interministerial $\left.\mathrm{n}^{\circ} 1.010 / 2006\right)$ contribuem para o exercício da alimentação e nutrição na escola, visto que deve ser desenvolvida em escolas de educação infantil, nível fundamental e médio de redes públicas e privadas. O Programa Saúde nas Escolas - PSE (Decreto nº. 6.286/2007) também contribui para a promoção da saúde, visando a integração e articulação da educação e da saúde, a fim de promover qualidade de vida para a população brasileira por 
meio de ações de educação em saúde no ambiente escolar e/ou nas unidades básicas de saúde (BRASIL, 2012).

Apesar de reconhecer os aspectos estruturais e relacionados à gestão que influenciam a qualidade da alimentação ofertada aos escolares, avaliamos que a contribuição possível do projeto seria a reflexão sobre o cardápio e sobre possibilidades de incluir maior variedade de preparações utilizando os insumos frequentemente disponíveis e, ao mesmo tempo, contemplando a variação de nutrientes e valorizando a cultura alimentar local.

Para tanto, foi proposto um Caderno de Receitas que será apresentado, junto com outras estratégias desenvolvidas, na discussão do próximo eixo.

\subsection{Planejamento e realização de intervenções: breve apresentação das práticas tornadas possíveis}

Neste eixo, apresentaremos brevemente as intervenções que foram realizadas, discutindo como acreditamos que as mesmas puderam contribuir para a promoção da alimentação saudável e da EAN na escola. A construção das intervenções foi baseada nos aspectos que foram apresentados nos eixos anteriores, como a reformulação dos objetivos e a inclusão de mais atores sociais da escola.

Foram desenvolvidas quatro intervenções junto aos escolares, sendo elas: 1) Exposição de vídeos com posterior criação de desenho com base no vídeo assistido; 2) Realização da dinâmica (Re)comendo; 3) Baralho do Processamento dos Alimentos; 4) Mostra Fotográfica Cores e Sabores. Foram elaborados ainda dois documentos destinados às professoras e merendeiras, sendo eles: o Caderno de Atividades; e o Caderno de Receitas da Alimentação Escolar.

A exposição de vídeos foi a estratégia utilizada para introduzir a abordagem sobre alimentação com os escolares, a partir de uma estratégia lúdica. Foram exibidos vídeos da série Nutriamigos (FRANCISCATO, 2010). Posteriormente, solicitamos aos alunos que criassem um desenho com base no vídeo assistido. Os desenhos foram analisados para que pudéssemos identificar os temas mais destacados pelos discentes. 
A realização da dinâmica (Re)comendo, proposta por Arce e colaboradores (2013), foi realizada de forma adaptada. Explorou-se os diferentes sentidos para identificação dos alimentos, buscando aumentar o repertório de experiências dos escolares, trazendo à discussão se o alimento era conhecido, a forma de preparo comumente realizada em casa, se gostavam ou não do alimento apresentado, entre outras questões.

O Baralho do Processamento dos Alimentos e a Mostra Fotográfica Cores e Sabores, por sua vez, foram elaboradas no contexto do projeto cuja experiência sistematizamos. As duas estratégias tiveram a intenção de trabalhar conceitos complexos, como o nível de processamento dos alimentos e a comensalidade, de maneira mais compreensível para os escolares.

A construção do Baralho se baseou na proposta de classificação dos alimentos apresentada no Guia Alimentar para a População Brasileira (2014). O Baralho contém 54 cartas e foi organizado para utilização das turmas de $4^{\circ}$ e $5^{\circ}$ anos. Cada carta contém a figura de um alimento e todos os alimentos são apresentados em três níveis de processamento. $\mathrm{O}$ desafio proposto ao jogador é a formação de trincas, combinando a representação do alimento in natura ou minimamente processado, processado e ultraprocessado.

A utilização deste jogo permitiu aos escolares conhecer mais sobre cada alimento e entender um pouco da sua transformação até se tornar um produto industrializado. Durante o jogo fomos desenvolvendo o diálogo sobre alimentação saudável e sobre a importância de preferir o alimento mais próximo do natural, consumindo moderadamente os industrializados.

Instrumentos como o baralho do processamento devem ser usados como meio para a promoção de discussões sobre a cadeia produtiva de alimentos, abordando desde onde vem o alimento até passar por todas as etapas de processamento, sobre os aspectos nutritivos e sobre o valor cultural que um alimento innatura e vindo da agricultura familiar, por exemplo, pode representar.

A Mostra Fotográfica Cores e Sabores foi realizada como uma atividade de encerramento do projeto na escola e teve como objetivo central aproximar os escolares da oferta de alimentos regionais. A Mostra Fotográfica retratou possibilidades de se pensar a 


\section{Revista
Debates Insubmissos}

alimentação saudável a partir dos mecanismos que a cidade e cultura regional oferecem, com ênfase nas feiras dos bairros, que oferecem alimentos in natura de baixo custo.

Para a produção das fotos, a equipe do projeto visitou duas das principais feiras de Salvador (Feira do Japão e Feira Dois de Julho) e bancas de frutas (estruturas simples, tipo mesa) do bairro em que a escola está localizada. As fotos foram realizadas com celulares, resultando em imagens que cumpriam o objetivo de registrar a variedade de produtos in natura, seus preços, cores e formas variadas.

Uma galeria de imagens foi apresentada nos corredores da escola, compondo uma combinação entre as fotos dos alimentos das feiras e os desenhos produzidos pelos alunos na primeira intervenção descrita. Além disso, a fim de apresentar os alimentos aos discentes, foi montada uma cesta com as frutas sazonais disponíveis na época e de baixo custo. Cuidamos para proporcionar uma boa apresentação dos alimentos, bem como reforçar a informação de que eles advinham da feira do bairro.

O diferencial dessa intervenção foi perceber no olhar dos escolares o reconhecimento da feira de alimentos do seu bairro, ao mesmo tempo em que havia curiosidade em conhecer as frutas que ainda não haviam consumido ou a surpresa com diferentes formas de apresentação de outras já conhecidas.

Mesmo alimentos já conhecidos puderam ser explorados de outro ponto de vista pelos escolares, pois ver o alimento em exposição, apreciar sua aparência e sentir seu sabor de modo orientado e intencional permitiu aos estudantes uma nova experiência alimentar. Por exemplo, ao tocar o melão e sentir o seu sabor, ouvimos várias vezes "posso pegar mais?" "eu nunca comi melão assim", colocando para a equipe a reflexão sobre o significado deste "assim".

Acreditamos que a intervenção Mostra Fotográfica Cores e Sabores permitiu explorar elementos essenciais à valorização da cultura alimentar regional, promoção da autonomia nas escolhas alimentares, incentivo aos familiares para a compra de alimentos na feira e ao preparo e consumo de alimentos acessíveis. 
Destacamos que todas as atividades descritas até aqui foram realizadas pela equipe do projeto, acompanhadas pelas professoras. Apesar de se apresentarem de forma coadjuvante, auxiliaram na lida com os escolares e presenciaram o desenvolvimento das atividades. Esta participação não configura a necessidade da equipe em tornar as professoras capacitadas para as ações de forma direta, no entanto foi possível a colaboração das mesmas.

Passando à descrição dos documentos criados, o Caderno de Receitas da Alimentação Escolar foi elaborado para auxiliar o trabalho das merendeiras. O Caderno apresenta 14 opções de receitas que utilizam os alimentos que estão disponíveis, e modos de preparo adequados às condições da cozinha da escola. $\mathrm{O}$ documento foi elaborado com o objetivo de auxiliar e valorizar a importância das merendeiras nas atividades escolares, colocando em destaque seu trabalho culinário. O caderno está dividido em seções que abordam pré-preparo, temperos e condimentos, e receitas.

No item sobre pré-preparo aborda-se a higienização dos alimentos, medidas caseiras e alguns tipos de cortes. $\mathrm{O}$ item destinado aos temperos e condimentos apresenta seus objetivos, utilização e reforça-se a importância de trocar temperos prontos por temperos naturais. Por fim, apresentam-se as receitas com rendimento, medida caseira e modo de preparo. Algumas das receitas apresentadas são Chocolate com Raspas de Laranja, Creme de Abóbora com Carne de Sertão, Torta de Arroz e Cenoura com Carne Moída, Lelê de Flocão de Milho. O caderno tem linguagem acessível e é ilustrado com fotos.

O Caderno de Atividades, destinado às professoras foi desenvolvido para auxílio em atividades com os escolares. O material apresenta atividades como, por exemplo, “Adivinhação - O que é o que é?”, envolvendo os alimentos e suas características, a fim de proporcionar por meio do raciocínio rápido conhecimento de forma descontraída. Composto por apresentação, objetivo, materiais utilizados e passo a passo para a realização da atividade; esse material foi adaptado dos Cadernos de Educação Alimentar e Nutricional: o direito humano à alimentação adequada e o fortalecimento de vínculos familiares e comunitários, do Ministério do Desenvolvimento Social e Combate à Fome (MDS). 
Os materiais foram construídos como incentivos e auxílio às professoras e merendeiras para trabalhar a promoção da alimentação saudável por meio de abordagens ativas, que dêem a chance aos educandos, educadores e atores sociais de construir autonomia e criticidade por meio da reflexão sobre a prática. Não encerram o processo de construção do conhecimento, mas de acordo com Paulo Freire (1996, p.18), o que "[...] precisa é possibilitar, que, voltando-se sobre si mesma, através da reflexão sobre a prática, a curiosidade ingênua, percebendo-se como tal, se vá tornando crítica".

Todas as intervenções desenvolvidas corroboram com os princípios para as ações de educação alimentar e nutricional, no que diz respeito às relações humanas, sociais e econômicas existentes no processo produtivo da cadeia alimentar, contemplando a alimentação em seus valores sociais, culturais, afetivos e sensoriais. Assim, a EAN se aproxima do sujeito, da sua vida real, estabelecendo vínculos entre os processos pedagógicos e as diversas necessidades familiares locais (BRASIL, 2012).

A elaboração das atividades citadas permitiu à equipe do projeto reconhecer as dificuldades do trabalho em campo, bem como de se incorporar os pressupostos teóricos nas mesmas. Porém, o enfrentamento do desafio favoreceu repensar as ações educativas, refletindo sobre o papel de nutricionistas enquanto profissionais que formam e que podem se formar a cada experiência vivida e compartilhada.

\section{PONTOS DE CHEGADA}

Como pontos de chegada, destacamos o processo reflexivo da equipe do projeto, que necessitou exercer a autocrítica e perceber-se resistente às demandas do campo de atuação e seus atores. A experiência sistematizada reforçou que o delineamento do processo formativo inclui uma relação dialógica que não pode ser desconsiderada.

Notamos que há uma necessidade de assimilação do papel da comunidade escolar como um todo, e compreensão da EAN como campo de conhecimento e prática transdisciplinar, intersetorial e multiprofissional superando "nutricionismos" e perspectivas de EAN que limitam seu papel e encobrem suas potencialidades. 
Também identificamos como um desafio persistente a reprodução de perspectivas tradicionais de saúde e educação, que reforçam a dimensão biológica da saúde, e mantêm a EAN nos limites da biologia e ciências. Ainda que os estudos sobre atuação de professores da rede básica de ensino enfatizem a necessidade de formação em temas específicos, o trabalho revelou que a modificação dos sentidos das atividades de EAN para os docentes e a inclusão dessas no bojo de suas atividades parecem ser condição fundamental para a construção de ações permanentes.

A dificuldade do reconhecimento desses profissionais enquanto promotores de saúde, e consequentemente de educação alimentar e nutricional, dificultou a construção colaborativa das atividades na escola. No entanto, foi possível contar com a cooperação de professoras no acompanhamento das atividades realizadas em suas salas.

Quanto às merendeiras, foi possível compreender o trabalho a partir da relação de afetividade com os escolares, e ainda a contradição sobre a alimentação escolar como pouco aceita. Porém, a alimentação escolar persiste entre o estigma e a valorização. Com isso, destaca-se a importância da observação da realidade e das perspectivas dos atores sociais envolvidos no projeto de intervenção.

Para a equipe extensionista, a criação e realização das intervenções permitiram vivenciar o campo de prática profissional de perto, aprendendo a superar os obstáculos apresentados com a própria experiência e considerando a ação-reflexão-ação como caminho para criticidade da prática atual e melhorias para uma próxima prática.

Como limitações do trabalho, apontamos a impossibilidade de utilizar métodos mais detalhados para a avaliação de cardápios, como o Avaliação Qualitativa das Preparações do Cardápio (AQPC), por exemplo, o que talvez pudesse atender mais diretamente às demandas das professoras quanto à análise da alimentação servida na escola. Além disso, não foi possível incluir a participação direta dos familiares dos estudantes nas ações desenvolvidas, ainda que sua importância fosse mencionada no momento das intervenções.

Por fim, aponta-se que os estudos sobre intervenções em EAN geralmente enfatizam seus objetivos e resultados, não dando ênfase ao processo vivido. Portanto, reforça-se a 
necessidade da sistematização e publicação de estudos de intervenção, construção e compartilhamento de materiais de apoio didático, uma vez que serve como auxílio à prática profissional no ambiente escolar e fora dele.

\section{REFERÊNCIAS}

ARCE, Alessandra; SILVA, Debora Alfaro São Martinho; VAROTTO, Michele. Os cinco sentidos. Universidade de São Carlos, 2013. Disponível em: $<\underline{\text { http://portaldoprofessor.mec.gov.br/fichaTecnicaAula.html?aula=25770 }}>$ Acesso em: 26 de junho de 2019.

ALBUQUERQUE, Alicinez Guerra. Conhecimentos e práticas de educadores e nutricionistas sobre a educação alimentar e nutricional no ambiente escolar. Dissertação (Mestrado em Nutrição) - Universidade Federal de Pernambuco, Recife, 2012.

ASBAHR, Flávia da Silva Ferreira. Sentido pessoal, significado social e atividade de estudo: uma revisão teórica. Revista Quadrimestral da Associação Brasileira de Psicologia Escolar e Educacional, São Paulo, v. 18, n. 2, p. 265-272, Maio/Agosto de 2014: .

BORSOI, Aline Tecchio; TEO, Carla Rosane Paz Arruda; MUSSIO, Bruna Roniza. Educação alimentar e nutricional no ambiente escolar: uma revisão integrativa. Revista Ibero-Americana de Estudos em Educação, v. 11, n. 3, p.1441-1460, 2016.

BRASIL. Ministério do Desenvolvimento Social e Combate à Fome. Marco de referência de educação alimentar e nutricional para as políticas públicas. - Brasília, DF: MDS; Secretaria Nacional de Segurança Alimentar e Nutricional, 2012.

BRASIL. Ministério da Saúde. Escolas promotoras de saúde: experiências do Brasil / Ministério da Saúde, Organização Pan-Americana da Saúde. - Brasília : Ministério da Saúde, (Série Promoção da Saúde; n. 6) 304 p. 2007.

BRASIL. Ministério da Saúde. Política nacional de alimentação e nutrição. Brasília, 2012. Disponível em: $<$ http://conselho.saude.gov.br/biblioteca/livros/politica_alimentacao nutricao.pdf $>$ Acesso em: 28 de abr de 2019.

BRASIL. Portaria Interministerial $n^{\mathbf{0}}$ 1.010, de 8 de maio de 2006. Institui as diretrizes para a promoção da alimentação saudável nas escolas de educação infantil, fundamental e nível médio das redes públicas e privadas, em âmbito nacional. Brasília, 2006.

BRASIL. Ministério da Educação. Resolução/CD/FNDE no 38, de 16 de julho de 2009. Dispõe sobre o atendimento da alimentação escolar aos alunos da educação básica no Programa Nacional de Alimentação Escolar - PNAE.

BRASIL. Decreto no . 6.286, de 5 de dezembro de 2007. Institui o Programa Saúde na Escola PSE, e dá outras providências. Diário Oficial [da] República Federativa do Brasil, Brasília, 6 
dez. 2007. Disponível em: $<$ https://www2.camara.leg.br/legin/fed/decret/2007/decreto-6286-5dezembro-2007-565691-publicacaooriginal-89439-pe.html> Acesso em: 28 de abr de 2019.

BRASIL. Ministério do Desenvolvimento Social e Combate à Fome (MDS). Cadernos de Educação Alimentar e Nutricional: o direito humano à alimentação adequada e o fortalecimento de vínculos familiares e comunitários; 2013.

CALVE, Tiago Morales; ROSSLER, João Henrique; SILVA, Graziela Lucchesi Rosa da. A aprendizagem escolar e o sentido pessoal na Psicologia de A. N. Leontiev. Revista Quadrimestral da Associação Brasileira de Psicologia Escolar e Educacional, São Paulo, v. 19, n. 3, p. 435-444, Setembro/Dezembro de 2015.

CAMOZZI, Aída Bruna Quilici; MONEGO, Estelamaris Tronco; MENEZES, Ida Helena Carvalho Francescantonio; SILVA, Priscila Olin. Promoção da Alimentação Saudável na Escola: realidade ou utopia? Cad. Saúde Colet., 23 (1): 32-7, Rio de Janeiro, 2015.

CERVATO-MANCUSO, Ana Maria; WESTPHAL, Marcia Faria; BÓGUS, Claudia Maria. O papel da alimentação escolar na formação dos hábitos alimentares. Rev Paul Pediatr; 31(3):324-30, São Paulo/SP, 2013.

CERVATO-MANCUSO, Ana Maria; VINCHA, Kellem Regina Rosendo; SANTIAGO, Débora Aparecida. Educação Alimentar e Nutricional como prática de intervenção: reflexão e possibilidades de fortalecimento. Physis Revista de Saúde Coletiva, 26 [ 1 ]: 225-249, Rio de Janeiro, 2016.

CARVALHO, Alice Teles de; MUNIZ, Vanessa Messias; GOMES, Josiane Fernandes; SAMICO, Isabella. Programa de alimentação escolar no município de João Pessoa - PB, Brasil. As merendeiras em foco. Interface - Comunicação, Saúde, Educação, v. 12, n. 27, p. 823834, out.-dez. 2008.

CAVALCANTE, Lília Iêda Chaves; CORRÊA Laiane da Silva. Perfil e trajetória de educadores em instituição de acolhimento infantil. Cadernos de Pesquisa, v. 42, n. 146, p. 494517, São Paulo, 2012.

COSTA, Ester de. Queirós; LIMA, Eronides da Silva; RIBEIRO, Vitória Maria Brant. O treinamento de merendeiras: Análise do material instrucional do Instituto de Nutrição Annes Dias Rio de Janeiro (1956-94). História, Ciências, Saúde Manguinhos. v. 9, n. 3, p. 535-360, set.-dez, 2002.

FERNANDES, Ana Gabriela de Souza; FONSECA, Alexandre Brasil Carvalho da; SILVA, Adilson Aderito da. Alimentação escolar como espaço para educação em saúde: percepção das merendeiras do município do Rio de Janeiro, Brasil. Ciência \& Saúde Coletiva, 19(1):39-48, Rio de Janeiro, 2014.

NUTRIAMIGOS, os super-heróis da nutrição infantil. Produção Suzana Janson Franciscato. PEN - Produção de Programa de Educação Nutricional Ltda.; HGN Produções. Bauru, São Paulo, 2010. 
FREIRE, Paulo. Pedagogia da autonomia: saberes necessários à prática educativa. 25 ed, São Paulo: Paz e Terra, 1996.

FREIRE, Paulo. Professora sim, tia não: cartas a quem ousa ensinar. São Paulo: Olho D’água, 1997.

GOMES, Kelly dos Santos. Cozinhando e dialogando: merendeiras, suas possibilidades e desafios para ações de educação alimentar e nutricional em escolas públicas do Rio de Janeiro. Dissertação (Mestrado) - Universidade Federal do Rio de Janeiro. Rio de Janeiro: UFRJ/NUTES, 2014.

GUITIERRES, Juliana Diniz; ELY, Stephany Sieczka; MOTA, Maria Renata Alonso; VIEIRA, Suzane da Rocha. O perfil dos alunos do curso de pedagogia da FURG. In: IX ANPED SUL. Seminário de Pesquisa em Educação da Região Sul, 2012, Rio Grande do Sul. Anais [...] Universidade Federal do Rio Grande - FURG, 2012.

MIZUKAMI, Maria da Graça Nicoletti. Ensino: as abordagens do processo. São Paulo: EPU, 1986

LEAO, Denise Maria Maciel. Paradigmas Contemporâneos de Educação: Escola Tradicional e Escola Construtivista. Cad. Pesquisa., São Paulo, n. 107, p. 187-206, July 1999.

PEREIRA, Patrícia da Rocha.; SCAGLIUSI, Fernanda. Baeza.; BATISTA, Sylvia Helena Souza da Silva. Educação nutricional nas escolas: um estudo de revisão sistemática. Nutrire, v. 36, n. 3, p. 109-129, 2011.

PICOLLI, Liana; CÔRREA, Elizabeth Nappi. O ensino da educação nutricional em escolas municipais rurais de um município do Oeste de Santa Catarina. Santa Catarina, 2013.

PIMENTA, Selma Garrido; FUSARI, José Cerchi; PEDROSO, Cristina Cinto Araujo; PINTO, Umberto de Andrade. Os cursos de licenciatura em pedagogia: fragilidades na formação inicial do professorpolivalente. Educ. Pesqui., São Paulo, v. 43, n. 1, p.15-30, jan./mar. 2017.

RAMOS, Flávia Pascoal; SANTOS, Ligia Amparo da Silva; REIS, Amélia Borba Costa. Educação alimentar e nutricional em escolares: uma revisão de literatura. Cad. Saúde Pública, 29(11):2147-2161, nov, Rio de Janeiro, 2013.

ROCHA, Aline dos Santos; FACINA, Vanessa Barbosa; Professores da rede municipal de ensino e o conhecimento sobre o papel da escola na formação dos hábitos alimentares dos escolares. Ciênc. Educ., Bauru, v. 23, n. 3, p. 691-706, 2017.

RUSCHEL, Letícia Fialho; HENN, Ruth Liane; BACKES, Vanessa; MELO, Priscila de; MARQUES, Luana Araújo da Silva; OLINTO, Maria Teresa Anselmo. Insegurança alimentar e consumo alimentar inadequado em escolares da rede municipal de São Leopoldo, RS, Brasil. Ciência \& Saúde Coletiva, 21(7):2275-2285, 2016.

SANTOS, Ligia Amparo da Silva; O fazer educação alimentar e nutricional: algumas contribuições para reflexão. Ciência \& Saúde Coletiva, 17(2):453-462, 2012. 
SÁ JUNIOR, Luis Salvador de Miranda. Desconstruindo a definição de saúde. Jornal do Conselho Federal de Medicina (CFM), pg 15-16, jul/ago/set de 2004. Acesso em: 15 de junho de 2019. Disponível em: $<$ http://www.dis.unifesp.br/pg/Def-Saude.pdf $>$

DA SILVA, Santuza Amorim; PÁDUA, Karla Cunha. Atores sociais da escola.In:OLIVEIRA, D.A.; DUARTE, A.M.C.; VIEIRA, L.M.F. DICIONÁRIO: trabalho, profissão e condição docente. Belo Horizonte: UFMG/Faculdade de Educação, 2010.

SOUZA, Evanice Avelino de; FILHO, Valter Cordeiro Barbosa; NOGUEIRA, Júlia Aparecida Devidé; JUNIOR, Mário Renato de Azevedo. Atividade física e alimentação saudável em escolares brasileiros: revisão de programas de intervenção. Cadernos de Saúde Pública, v. 27, n. 8, p. 1459-1471, ago. 2011.

SCHMITT, Miguel Ângelo; Ação-Reflexão-Ação: A Prática Reflexiva como elemento transformador do cotidiano educativo. Protestantismo em Revista, São Leopoldo, RS, v. 25, maio.-ago, 2011. Disponível em: http://www.est.edu.br/periodicos/index.php/nepp. Acesso: 15 abr de 2019.

SZINWELSKI, NadiaKunkel; LALANA, Aline; MARIOTTI, Eduarda; BELUSSO, Janaévi; GALLINA, Luciara Souza; TEO, Carla Rosane Paz Arruda; A autopercepção do papel da merendeira no espaço escolar. In: Management, Educationand Health PromotionConference. CONVIBRA, 2015. Disponível em: http://www.convibra.com.br/upload/paper/2015/58/ 2015_58_11402.pdf Acesso em: 21 de junho de 2019.

Submetido em: 21/07/2019

Aprovado em: 09/08/2019 